\title{
Effect of Cultural Intelligence on the Work Adjustment of PE Teachers in Primary and Secondary Schools in a Large City in Iran
}

Authors' contribution:
A) conception and design of the study
B) acquisition of data
C) analysis and interpretation of data
D) manuscript preparation
E) obtaining funding

\section{Hamidreza Mirsafian}

University of Isfahan, Iran

This study aimed to measure the cultural intelligence of physical education (PE) teachers' work adjustment in primary and secondary schools in a large city in Iran (Isfahan). The method of this research was descriptive (correlation) and the total population included all of the PE teachers at three educational levels in Isfahan in 1393 (2014) $(\mathrm{N}=559)$. Participants $(\mathrm{N}=226)$ were selected by using the stratified random sampling method according to the total population of the PE teachers in all six educational regions of Isfahan. A self-constructed cultural intelligence questionnaire (20 items) as well as a work adjustment scale (Davis \& Lofqist, 1991) including 20 items were employed in this research. The regression and correlation tests were used for analyzing data. The results indicated that cultural intelligence significantly affects the PE teachers' work adjustment. There was also a significant correlation between cultural intelligence and the PE teachers' work adjustment.

cultural intelligence, motivation, PE teachers, value, work adjustment

\section{Introduction}

Enhancing organizational performance and increasing productivity are among the key objectives of organizations for achieving sustainable development in today's complicated world. In this regard, the role of human resources, especially in varying occupational and organizational conditions, is of particular importance. Cultural intelligence is one of the concepts that have considerable impacts on employee job performance in organizations. Cultural intelligence refers to the ability for personal growth through continued learning and a better understanding of cultural heritage, customs and values, and effective behavior with people of different cultural backgrounds and different perceptions. Earley and Ang (2006) define cultural intelligence as the ability of an individual to effectively adapt to new cultural forms. They believe that the structure of cultural intelligence is linked to other types of intelligence, including emotional and social intelligence. Earley and Ang (2006) explain cultural intelligence in four dimensions: 
Cultural intelligence strategy refers to the way an individual comprehends intercultural experiences. This strategy implies the processes a person employs to obtain and understand cultural knowledge. This occurs when individuals judge their own thinking processes and those of others.

Cultural intelligence knowledge refers to an individual's understanding of cultural similarities and differences related to understanding economic and legal systems, norms, social interactions, religious beliefs, and aesthetic values in other cultures.

Cultural intelligence motivation refers to an individual's level of interest to try and experience other cultures and to interact with people from different cultures. This motivation includes the intrinsic value that multicultural interactions and self-confidence have for individuals, which allows an individual to act effectively in different cultural contexts.

Cultural intelligence behavior refers to the capability of an individual to use the verbal and non-verbal behaviors that are appropriate in dealing with different cultures. This type of intelligence is the ability to adapt to other norms, values, and different national, ethnic, and organizational cultures, and allows the individual to behave appropriately in any context.

Triandis (2006) describes the ability to delay judgment as an important element in cultural intelligence. A number of factors, such as contextual pressures, personal experiences, and characteristics, affect the attitudes and behaviors of people. Therefore, a person with an appropriate level of cultural intelligence is able to make judgments and decisions about issues based on adequate and comprehensive information. In fact, cultural intelligence is a new range of intelligence which has a great association with diverse work environments besides being considered an effective factor in the work adjustment of employees in organizations.

Many scientists believe that work adjustment is one of the most important factors that have great effect on employee success in organizations and thus increase job performance and organizational productivity. Dawis and Lofquist (1991) studied work adjustment in four areas of personality adjustment, values and needs adjustment, adjustment with work environment, and job satisfaction, which serve as the basis of the present research for the assessment of work adjustment.

In any organization, work adjustment and job satisfaction lead to the improvement of performance. Accordingly, managers in any organization desire to find strategies to increase the level of work adjustment of their staff. Among these organizations is the Ministry of Education in Iran, which always attempts to improve teachers' performance, as this has a significant impact on the education and social modernization of the society. The role of physical education (PE) teachers in Iran is different from that of other teachers. In fact, they are pioneers in developing the culture of health, movement, and vitality in Iran's schools. In spite of this, little attention has been paid to this group of teachers compared to other teachers regarding both economic and social aspects. Indeed, although they are the founders and creators of students' attitudes and tendencies toward sports, they are not considered to be very important (Poursoltani Zarandi, Faraji \& Allahyari, 2011). According to Koldi and Asgari (2002) and Jahangardi (2008), although the policies of the Ministry of Education in Iran encourage the job satisfaction of teachers, these policies have not yet been completely enforced, and some teachers in Iran, especially teachers of PE, do not get the appropriate satisfaction from their jobs. This can have a strong effect on their performance at school. Consequently, it is important to analyze the factors affecting the performance, education quality, and job satisfaction of this group of teachers in Iranian society. Thus, the present research aims to assess the effect of cultural intelligence in the job adjustment of PE teachers in primary and secondary schools in Iran.

\section{Review of literature}

Various studies have been conducted in connection with cultural intelligence and its impact on various aspects of job adjustment and performance. For instance, the research of Haghighatian, Sadeghi, and Shahcheraghi (2014) attempted to measure the effect of cultural intelligence on the job performance of employees in various organizations. They reported that cultural intelligence is one of the effective factors in the field of organizational relations. In their opinion, cultural intelligence increases individuals' credibility and 
power of judgment. It improves logical and unbiased thinking processes in employees, affects effective interaction and relationships with others, boosts the adjustment ability of the individuals in the organization, and, ultimately, enhances their work adjustment. In his study, Tan (2004) indicates that individuals who benefit from a higher level of cultural intelligence have more adjustment with their work environment, are more satisfied with their jobs, and generally enjoy more work adjustment. Van Driel (2011) also sees cultural intelligence as a factor for increasing the work adjustment of employees and considers it effective for organizations in achieving their objectives.

In organizational intelligence theory, Albert (2005) considers cultural intelligence to be one of the key factors affecting intra-organizational relations and even regards it as a requirement of organizational intelligence. According to him, the existence and the promotion of cultural intelligence are essential for the job satisfaction of employees and the success and progress of each organization. Prado (2006) also believes that employees who are more able to evaluate cultural and business opportunities have higher levels of job satisfaction and work adjustment, as well as higher cultural intelligence compared to other employees in the organization. Additionally, there are some studies suggesting that individuals with high cultural intelligence enjoy higher flexibility and work adjustment: interestingly, they act flexibly in the face of organizational changes and can easily adapt to the organization environment (Kazemi, 2013). In his research on the assessment of the impact of cultural intelligence on psychological adjustment, social-cultural adjustment, and employee work adjustment, Williams (2008) held that individuals with higher levels of cultural intelligence are more motivated to continue their jobs and achieve occupational successes. He thinks that these people are more coordinated with the organization and organizational changes and have higher social connections that are considered useful for any organization. In another study examining the cultural intelligence relationship with work adjustment and the organizational confidence of Iranian university faculty members, Keykhanezhad and Ghanadi (2014) indicate that there is a positive correlation between cultural intelligence and components of work adjustment. They also regard cultural intelligence as a factor in predicting the level of work adjustment in the faculty members of Iranian universities.

\section{Method}

\section{Participants}

This study was conducted among all of the PE teachers employed at the primary and secondary schools in Isfahan, ${ }^{1}$ Iran $(\mathrm{N}=559)$ in 2015. Participants in this study $(\mathrm{N}=226)$ were selected through the stratified random sampling method, from the age range of 23-45 (mean=29.2; $\mathrm{SD}=4.7)$ and from two educational levels, $\operatorname{BSc}(n=177,78.3 \%)$ and MSc $(n=49,21.7 \%)$. The number and percentage of participants in each educational district in Isfahan is reported in Table 1.

Table 1. Total and Selected Participants

\begin{tabular}{ccccc}
\hline Educational District & Total Population & \multicolumn{3}{c}{ Participants } \\
& N & P & N & P \\
\hline District 1 & 51 & 9.2 & 21 & 9.3 \\
District 2 & 92 & 16.4 & 37 & 16.4 \\
District 3 & 119 & 21.3 & 48 & 21.2 \\
District 4 & 118 & 21.1 & 48 & 21.2 \\
District 5 & 114 & 20.4 & 46 & 20.4 \\
District 6 & 65 & 11.6 & 26 & 11.5 \\
Total & 559 & 100 & 226 & 100 \\
\hline
\end{tabular}

Source: own study.

\footnotetext{
${ }^{1}$ Isfahan is the second largest city in Iran (after Tehran) and is located in the center of country. The population of this city is around two million, and a large portion of that population is under 30 years old.
} 
The sample of this study fairly represents the total population according to the educational district that PE teachers employed at as well as level of education of PE teachers.

\section{Instruments and measurements}

Two questionnaires were employed in this research. The first questionnaire measured work adjustment (Dawis, \& Lofqist, 1991). This scale includes 20 questions and 4 dimensions (personal adjustment with job, conformity of values and needs with job, adjustment with job environment, and job satisfaction). The reliability and validity of the questionnaire was reported at 0.88 and 0.81, respectively, by Dawis and Lofqist (1991). In this study, the reliability of the questionnaire is fixed between 0.85 and 0.87 using Cronbach's alpha test.

The second scale was employed for measuring cultural intelligence. This questionnaire was developed in the US Cultural Intelligence Center (2012) and the scale includes 20 questions and 4 dimensions (cultural intelligence strategy, cultural intelligence knowledge, cultural intelligence motivation, and cultural intelligence behavior). The reliability and validity of this scale were reported at 0.90 and 0.82 , respectively, by the US Cultural Intelligence Center. The reliability of the questionnaire was also measured for this research using Cronbach's alpha test and was fixed between 0.82 and 0.86 .

Participants were asked to respond to both of the questionnaires with a 5-point Likert scale, ranging from 5 = strongly agree to 1 = strongly disagree.

\section{Statistical analysis}

A Pearson correlation test as well as a regression test were used for analyzing the data. The IBM SPSS Statistics 19 was employed in this research.

\section{Results}

The results of this study indicated that there is a positive relationship between cultural intelligence and work adjustment in PE teachers ( $\mathrm{p} \leq 0.05)$ (Table 2). In other words, improving the cultural intelligence among $\mathrm{PE}$ teachers results in increasing their work adjustment.

A correlation test was also used for measuring the relationship between the cultural intelligence and work adjustment dimensions of PE teachers. The results showed a significant relationship between cultural intelligence and the three dimensions of work adjustment (personal adjustment with job, adjustment with job environment, and job satisfaction) among PE teachers $(\mathrm{p} \leq 0.05)$. In other words, developing cultural intelligence in PE teachers improves their personal adjustment with their job, increases their adjustment with the job environment, and improves their job satisfaction (Table 2).

Table 2. Results of the correlation test between cultural intelligence and work adjustment dimensions among PE teachers

\begin{tabular}{lcccc}
\multicolumn{1}{c}{ Source } & F & r & Effect Size & Sig \\
\hline $\begin{array}{l}\text { Cultural intelligence/personal } \\
\text { adjustment with work }\end{array}$ & 226 & 0.43 & 0.17 & 0.03 \\
$\begin{array}{l}\text { Cultural intelligence/adjustment with } \\
\text { values and norms }\end{array}$ & 226 & 0.18 & 0.03 & 0.18 \\
$\begin{array}{l}\text { Cultural intelligence/adjustment with } \\
\text { job environment }\end{array}$ & 226 & 0.40 & 0.16 & 0.04 \\
$\begin{array}{l}\text { Cultural intelligence/job satisfaction } \\
\text { Cultural intelligence/work adjustment }\end{array}$ & 226 & 0.42 & 0.17 & 0.03 \\
\hline
\end{tabular}

Source: won study.

A regression test was also employed to clarify the relationship between variables of the study. The results indicated that cultural intelligence is a significant predictor for work adjustment $(\mathrm{p} \leq 0.05)$. In other words, it can be significantly predicted that developing cultural intelligence among PE teachers leads to an increase in the level of adjustment with their work (Table 3). Also, based on the results, it is predicted that improving 
cultural intelligence among PE teachers leads to increasing personal adjustment to their job. Similarly, it leads to improving levels of job satisfaction and also leads to an increase in the level at which they adjust to the job environment at schools $(\mathrm{p} \leq 0.05)$ (Table 3 ).

Table 3. Results of the regression test between the cultural intelligence and work adjustment dimensions among PE teachers

\begin{tabular}{lcccccc}
\hline \multicolumn{1}{c}{ Dimension } & $\begin{array}{c}\text { Unstandardized } \\
\text { Coefficient }\end{array}$ & Std. Error & Beta & $\mathbf{t}$ & $\begin{array}{c}\text { Coefficient of } \\
\text { Determination }\end{array}$ & Sig \\
\hline $\begin{array}{l}\text { Personal adjustment with job } \\
\begin{array}{l}\text { Conformity of values and } \\
\text { needs with job }\end{array}\end{array} \quad 0.12$ & 1.13 & 0.89 & 2.62 & 0.23 & 0.01 \\
$\begin{array}{l}\text { Adjustment with job } \\
\text { environment }\end{array}$ & 0.15 & 0.67 & 0.14 & 0.20 & 0.05 & 0.84 \\
Job satisfaction & 0.18 & 1.10 & 0.80 & 2.41 & 0.23 & 0.02 \\
Job adjustment & 0.16 & 1.12 & 0.83 & 2.48 & 0.25 & 0.01 \\
\hline
\end{tabular}

Source: own study.

\section{Discussion}

PE teachers should have high work adjustment and performance since they play a major role in shaping students' attitude and tendency toward sports and physical activities. According to the results of this research, cultural intelligence has been an effective component of PE teachers' personality adjustment with work and their adjustment to the work environment. In other words, if PE teachers in Iran have higher cultural intelligence, it can be predicted that their adjustment with work and the work environment will increase.

Based on the results, there is a positive correlation between cultural intelligence and the work adjustment of PE teachers. To put it simply, the existence and strengthening of cultural intelligence among PE teachers will increase their work adjustment. Other results also indicated that there is a positive and significant correlation between cultural intelligence and PE teachers' personality adjustment to their work, their adjustment to the work environment, and their job satisfaction. As a result, the promotion of cultural intelligence among PE teachers increases their personality adjustment to work, adjustment to the work environment, and their job satisfaction.

These findings are supported by the results of studies made by Perado (2006), Tan (2004), Taslimi, Gholipour, Verdinejad, and Man Al Agha (2010), Haghighatian, Sadeghi, and Shahcheraghi (2014), Delaram (2009), Shahcheraghi (2013), Kazemi (2009), Keykhanejad and Ghanadi (2014), Nazemi, Fayazi, and Simarasl (2010), Naeechi and Abbasalizade (2008), Van Driel (2008, 2011), Williams (2008), and Yazdekhasti (2010).

In Earley and Ang's theory (2006), cultural intelligence includes the ability to successfully adapt to the new environment and have a greater effective relationship with other people and the new work environment. In other words, a new work environment requires high adjustment skills. That is why people with high cultural intelligence can easily adjust to the conditions of new work environments with different organizational cultures. It can be claimed that cultural intelligence increases the individual's adjustment power since his/her judgment will be based on a positive attitude in any situation, and this influences his/her adjustment.

Earley and Mosakowski (2004) believe that a large part of cultural intelligence can be learned and thus generated and promoted through learning and education. Accordingly, it seems necessary to attempt to create and strengthen cultural intelligence among PE teachers in Iran. This becomes more important when focus is placed on the inconspicuous role and status of PE teachers in comparison with other school teachers in Iranian society.

Consequently, it is recommended that those responsible for the education system in Iran take the present research results, as well as other related research findings, into consideration in order to increase the work adjustment of PE teachers and thus their work performance. 


\section{REFERENCES}

Albert, K. (2005). Social Intelligence: The New Science of Success. New York: Amazon.

Cultural Intelligence Center of the USA (2012, April). Cultural intelligence scale. Retrieved April 14, 2010 from http://culturalq.com/

Dawis, R.V., \& Lofqist, L.H. (1991). A psychological theory of work adjustment. Minneapolis: University of Minnesota Press.

Delaram, T. (2009). Tasir-e Hush-e Farhangi Bar Amalkard-e Modiran-e Bank-e Eghtesad Novin Dar Ostan-e Tehran /Effect of cultural intelligence on the performance of Eghtesad Novin Bank Managers in Tehran Province/. Unpublished master's thesis. Iran: Ferdosi University.

Earley, P.C., \& Ang, S. (2006). CQ: Developing cultural intelligence at work. California: Stanford Business Book.

Early, C., \& Mosakowski, E. (2004). Cultural intelligence. Harvard Business Review, 129-136.

Haghighatian, M., Sadeghi, S., \& Shahcheraghi, F. (2014). Baresi-e Tasir-e Hosh-e Farhangi Bar Amalkard-e Shoghli-e Karkonan-e Behzisti (Mored-e Motaleae: Karkonan-e Behzisti-e Shahr-e Isfahan) /Study of the effect of cultural intelligence on job performance among Well Life Organization staff (A case study: Well Life Organization staff of Isfahan)/. Applied Sociology, 25(4), 59-72.

Jahangardi, A. (2008). Baresi-e Rabete Bein-e Khososiat-e Shakhsiati ba Khodpendare Shoghli Va REzayat-e Shoghli Dar Mian-e Moaleman-e Dabiran-e Motavasete Shahr-e Bojnud Study of the relationship between personality characteristics and job self-concept and job satisfaction among high school teachers in Bojnud/. Unpublished master's thesis. Iran: Allame Tabatabaei University.

Kazemi, M. (2013). Baresi-e Ertebat-e Hush-e Farhangi ba Amalkard-e Karkonan-e Jameae Almostafa Alalamiyeh /Study of the relationship between cultural intelligence and performance of the Mostafa Al Alamiyeh staff/. Unpublished master's thesis Iran: Tehran University.

Keykhanezhad, M,. \& Ghanadi, S. (2014). Baresi-e Rabeteye Hush-e Farhangi Ba Sazgari-e Shoghli va Etemad-e Sazmani-e Azaye Heiat-e Elmi /Study of the relationship between cultural intelligence with job adjustment and organizational trust among academic staff/. Occupational and Organizational Consulting, 5(15), 114-128.

Koldi, A., \& Asgari, G. (2002). Baresi-ye Mizan-e Rezayat-e Sghoghli-e Moaleman-e Amuzesh Va Parvaresh-e Shahr-e Tehran /Study on the job satisfaction level of primary teachers in Tehran/. Journal of Psychology and Educational Sciences, 33(1), 103-120.

Nazemi, S., Fayazi, M., \& Simarasl, N. (2010). Baresi-ye Rabete-ye Hush-e Atefi Va Hush-e Farhangi Dar Bein-e Daneshjuyan- Daneshgah-e Ferdosi-ye Mashhad Va Tasir-e Tahsilat-e TAkmili Bar An /Study on the relationship between emotional intelligence and cultural intelligence among Ferdosi Mashhad University students and its effect on postgraduate study/. Psychology, 44, 43-55.

Poursoltani Zarandi, H., Faraji, R., \& Allahyari, M. (2011). Ertebat-e Mian-e Sabkhay-e RAhbari-e Modiran-e Madares Va Niazha-ye Angizeshi-e Moaleman Tarbiat Badani Bar Asas-e Nazarei-ye Mc Gregor /Relationship between leadership styles of school managers and motivational needs of PE teachers, based on the McGregor theory/. Study in Sport Management and Motor Behavior, 2(4), 73-85.

Prado, W.H. (2006). The relationship between cultural intelligence and perceived environmental uncertainty. Arizona: University of Phoenix.

Shahcheraghi, F. (2013). Baresi-e Rabete-ye Mian-e Hush-e Farhangi Ba Amalkar-e Ejtemaei- Shoghli-e Karkonan-e Edare Behzisti Ostan-e Isfahan /Study on the relationship between cultural intelligence with social-career performance of Well Life Organization staff in Isfahan/. Unpublished master's thesis. Iran: Islamic Azad University of Dehaghan Branch.

Tan, J.S. (2004). Cultural intelligence and the global economy. Leadership in Action, 24, 101-112.

Taslimi, M.S., Gholipour, A., Verdinejad, F. \& Man Al Agha, M. (2010). Erae-ye Rahkaryaei Baraye Ertegha-e Hush-e Farhangi Modiran-e Dolati-ye Omur-e Beinolmelal /Providing the guidelines for improving managers' cultural intelligence in international affairs/. Management Studies, 44, 29-57.

Triandis, H.C. (2006). Cultural intelligence in organization. Group \& Organization Management, 31(1), 20-26.

Van Driel, M. (2011). Personality, cultural intelligence, and cross-cultural adaptation. Organization Management, 44(1), $222-231$. 
Van Dyne, L. (2008). Development and validation of CQS: The cultural intelligence scale. In S. Ang \& L. Van Dyne (Eds), Handbook of cultural intelligence: Theory, measurement, and applications. New York: M.E. Sharp Inc.

Williams, M.E. (2008). Individual differences and cross-cultural adaptation: A study of cultural intelligence, psychological adjustment, and socio-cultural adjustment. Unpublished doctoral dissertation. LA: TUI University.

Yazdekhasti, G. (2010). Baresi-e Hush-e Farhangi Va Avamel-e Moaser Bar An Dar Mian-e Sakenin-e Shahr-e Isfahan SStudy on cultural intelligence and the factors that affect the citizens of Isfahan/. Unpublished master's thesis. Iran: Islamic Azad University of Khorasgan Branch.

AUTHOR'S ADDRESS: $\quad$ Hamidreza Mirsafian

University of Isfahan

Daneshgah Street, University of Isfahan

Isfahan, Iran

E-mail: Hamid.Mirsafian@gmail.com

Received: 6 September 2016; Accepted: 14 October 2016 